\title{
Choose MyPlate: Reduce Your Sodium ${ }^{1}$
}

\section{Ashley Hamm, Shari Bresin, D’Alicia Straughter, Karla P. Shelnutt, and Gail P. A. Kauwell²}

MyPlate, the icon released from the United States Department of Agriculture (USDA) in 2011, represents recommendations from the Dietary Guidelines for Americans. MyPlate is a tool developed to promote health and help Americans improve their eating habits. The U.S. Department of Health and Human Services and U.S. Department of Agriculture update the Dietary Guidelines for Americans every five years to keep it current with nutrition science. The new edition is from 2020-2025.

Reducing sodium intake is one of the MyPlate recommendations for healthy eating. Most Americans eat more sodium than they need, which can have negative health effects. This publication provides facts about sodium and the importance of reducing sodium intake. It also provides easy tips to reduce your sodium intake.

\section{What is sodium?}

Sodium is a mineral needed in small amounts by our bodies to work properly. It helps with fluid balance, nerve function, and muscle action (Mayo Clinic, 2019). We get most of our sodium from the foods we eat. However, if you eat too much sodium, it can be unhealthy for your body. The most common source of sodium in the diet is salt. This includes salt added to food during cooking and at the table. It also includes salt already in foods.

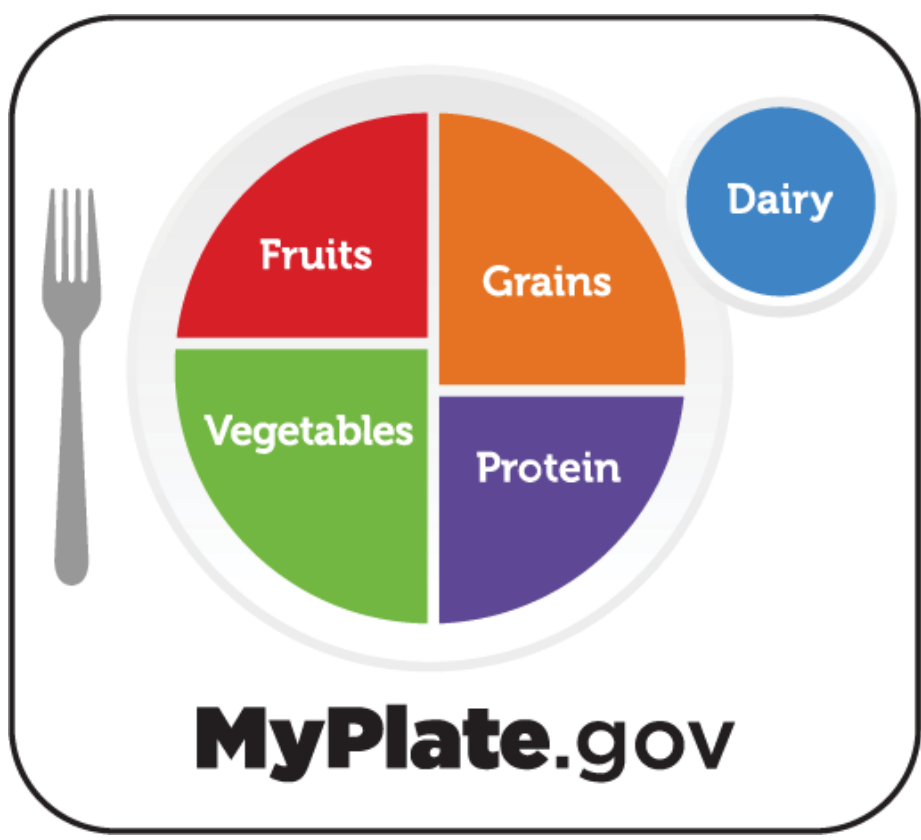

Figure 1. USDA's MyPlate recommends that most Americans reduce the sodium in their diets. This fact sheet contains information about sodium and tips to reduce your sodium intake.

Credits: http://www.myplate.gov

\section{How much should I be getting?}

According to the Dietary Guidelines for Americans 2020-2025, sodium intake should not exceed 2,300 milligrams in a day. Daily sodium intake for individuals ages 13 and younger should be below 2,300 milligrams.

1. This document is FCS80027, one of a series of the Department of Family, Youth and Community Sciences, UF/IFAS Extension. Original publication date April 2013. Revised November 2021. Visit the EDIS website at https://edis.ifas.ufl.edu for the currently supported version of this publication.

2. Ashley Hamm, dietetic intern, Master of Science-Dietetic Internship Program, Food Science and Human Nutrition Department; Shari Bresin, Extension agent I, M.N.M., family and consumer sciences, UF/IFAS Extension Pasco County; D'Alicia Straughter, Extension agent, family and consumer sciences, UF/IFAS Extension Bradford County; Karla P. Shelnutt, PhD, RD, associate professor, Extension nutrition specialist, Department of Family, Youth and Community Sciences, and nutrition program leader; and Gail P. A. Kauwell, professor, distinguished teaching scholar emeritus, former MS-DI program director, Food Science and Human Nutrition Department; UF/IFAS Extension, Gainesville, FL 32611.

The Institute of Food and Agricultural Sciences (IFAS) is an Equal Opportunity Institution authorized to provide research, educational information and other services

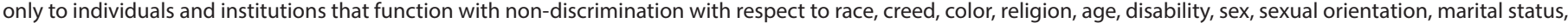

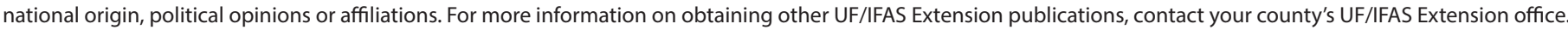
U.S. Department of Agriculture, UF/IFAS Extension Service, University of Florida, IFAS, Florida A \& M University Cooperative Extension Program, and Boards of County Commissioners Cooperating. Nick T. Place, dean for UF/IFAS Extension. 


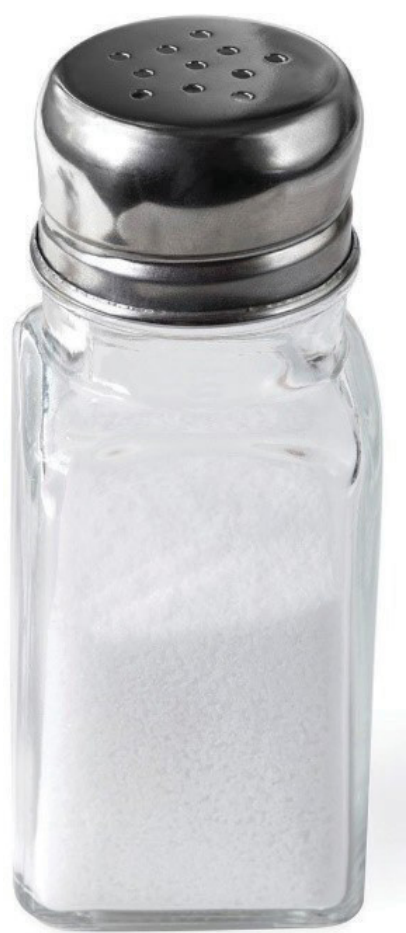

Figure 2. Our bodies need the mineral sodium to work properly, but too much can be unhealthy. Most of the sodium in our diet comes from salt.

Credits: iStockphoto

\section{How much is too much?}

Most Americans consume more sodium than they need. To avoid health risks associated with eating too much sodium, such as hypertension, children and adults should try to lower their sodium intake to less than 2,300 milligrams per day. Certain risk factors increase the chances of hypertension, such as age, race, lifestyle habits such as smoking and drinking, being overweight, or having a family history of hypertension. Talk to your doctor about any of these risk factors and possibly lowering sodium intake even further (to 1,500 milligrams per day) (MedlinePlus, 2021). Many Americans find it hard to limit their sodium intake to less than this amount, but it is possible. As you start to lower your sodium intake, your taste buds will adjust. Eventually you will find that you will need less sodium to be satisfied.

\section{Why should I reduce my sodium intake?}

If you eat too much sodium, it can cause high blood pressure. High blood pressure can damage your blood vessels and organs. This can lead to serious health problems such as heart disease, kidney disease, and stroke (Mayo Clinic, 2020). If you have high blood pressure, reducing your sodium intake, along with eating a well-balanced diet, may help reduce your blood pressure to normal levels (Mayo Clinic, 2021).

\section{How can I lower my sodium intake?}

Lowering your sodium intake is possible! Use the following tips to help you reduce your sodium intake.

\section{Know Your Foods}

The first step to reduce your sodium intake is to know where your sodium is coming from. The main sources of sodium in a typical diet are from three places. Sodium is found naturally in foods such as vegetable and dairy products. Sodium is also added to processed foods such as bread, pizza, fast food, and restaurant food. Lastly, sodium can be added to foods during cooking or at the table by using table salt or condiments. Table 1 lists some high-sodium foods and lower-sodium foods.

Table 1. Examples of high-sodium and low-sodium foods.

\begin{tabular}{|l|l|}
\hline High-Sodium Foods & Low-Sodium Foods \\
\hline $\begin{array}{l}\text { Canned vegetables, soups, and } \\
\text { beans }\end{array}$ & $\begin{array}{l}\text { Fresh and canned fruits } \\
\text { Fresh vegetables and canned } \\
\text { vegetables that say "No Salt } \\
\text { Added," "Low-Sodium," or } \\
\text { "Reduced Sodium" on the label }\end{array}$ \\
\hline $\begin{array}{l}\text { Sausages/cured meats, canned } \\
\text { meats, and lunch meats }\end{array}$ & $\begin{array}{l}\text { Fresh meats (poultry, beef, } \\
\text { seafood, pork) and eggs }\end{array}$ \\
\hline $\begin{array}{l}\text { Sauces and condiments (soy } \\
\text { sauce, mustard, ketchup, salted } \\
\text { butter) }\end{array}$ & $\begin{array}{l}\text { Vinegar, "low-sodium" dressings, } \\
\text { mayonnaise, and unsalted butter }\end{array}$ \\
\hline Salted nuts & Unsalted nuts \\
\hline Cheeses & $\begin{array}{l}\text { Fat-free milk, low-fat milk, } \\
\text { yogurt, and ice cream }\end{array}$ \\
\hline Pre-packaged or instant meals & $\begin{array}{l}\text { "No Salt Added" or "Low-Sodium” } \\
\text { pre-packaged foods }\end{array}$ \\
\hline $\begin{array}{l}\text { Salted popcorn, crackers, chips, } \\
\text { and pretzels }\end{array}$ & $\begin{array}{l}\text { Unsalted popcorn, crackers, } \\
\text { pretzels, and chips }\end{array}$ \\
\hline
\end{tabular}

\section{Read the Label}

The Nutrition Facts label is printed on all packaged food products. The amount of sodium per serving of food is listed on the label. Pay attention to the serving size on the label. Most packages of food contain more than one serving. The sodium content is given in both milligrams (mg) per serving and \% Daily Value. The \% Daily Value is based off of an eating pattern of 2,300 $\mathrm{mg}$ of sodium a day. However, depending on one's individual needs and health conditions, this may be too much.

A sodium content of $20 \%$ or greater ( 460 milligrams) is high. A sodium content of $5 \%$ or less (115 milligrams) is low (FDA, 2021). Aim for less than $100 \%$ of the Daily Value. (For more information on how to read a food label, 
see EDIS publication FSHN17-5, The New Nutrition Facts Label, at https://edis.ifas.ufl.edu/publication/FS300). You can reduce your sodium intake by choosing foods lower in sodium. Look for packaging that says "low sodium," "reduced sodium," "unsalted," and "no salt added." While these products may still contain some sodium, they are lower in sodium than "regular-sodium" products.

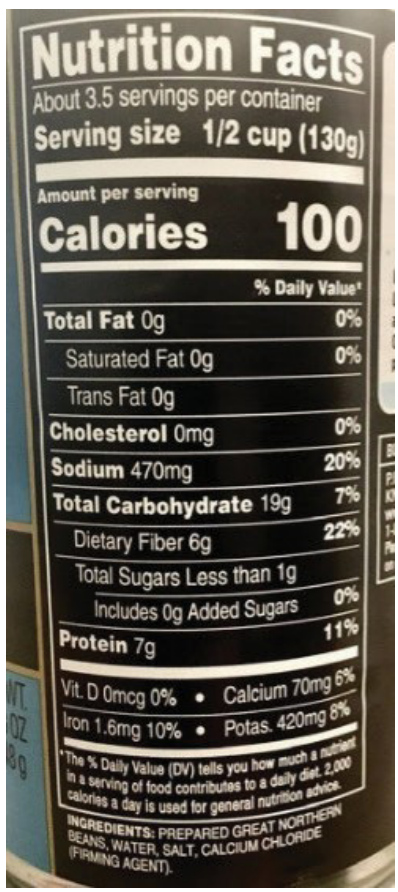

Figure 3. Read the Nutrition Facts label to find out how much sodium is in the foods you are eating. If the sodium content is $20 \%$ or more, then the sodium is high.

\section{Choose Fresh}

Processing increases the sodium content of foods. These foods include canned soups, lunch meats, and cheese. Instead, try fresh versions of these foods to lower the amount of sodium you eat. These foods include fresh fruits and vegetables, unsalted nuts, dried beans, whole grains, and fresh meats (not cured or precooked).

In addition to reading the Nutrition Facts label, make sure you read the ingredients list. With highly processed foods, the sodium source may come from ingredient names you are not familiar with, such as food additives or preservatives (American Heart Association, 2018):

- Sodium citrate

- Sodium diacetate

- Sodium nitrate

- Sodium phosphate

- Trisodium phosphate
Meanwhile, common ingredients that contain sodium include:

- Sodium chloride (table salt)

- Himalayan pink salt

- Kosher salt

- Monosodium glutamate (MSG)

- Sodium bicarbonate (baking soda)

\section{Savor Home-Cooked Meals}

Know what is in your food! The best way to know what you are eating is to prepare it yourself. Choose low-sodium ingredients and limit the amount of salt and other sodiumcontaining ingredients and seasonings you add. By doing this, you can easily lower the amount of sodium in your diet. For many recipes, you can reduce the amount of salt by half without compromising the flavor. Make sure to drain and rinse canned beans, veggies, and tuna.

\section{Get creative!}

Instead of adding salt or high-sodium condiments to your foods, use tasty spices, herbs, garlic, lemon juice, or vinegar. Using these instead of salt will reduce your sodium intake without losing taste. Be careful, however, because some spices and seasoning mixes have sodium added and are therefore higher in sodium. Higher-sodium seasonings include packets of chili powder, taco seasoning, bouillon, seasoning salts (such as garlic salt and onion salt), and MSG (Foods High In.net, 2021).

All types of salts, including sea salt, pink salt, rock salt, and other popular salts, have nearly the same sodium content as regular table salt. If salt is in the name of the seasoning or the ingredient list, it is probably high in sodium. There are many delicious, lower-sodium spices that can add flavor to your food. Try using curry, pepper, rosemary, basil, oregano, cilantro, paprika, dill, or any other fresh herb that sounds good. Get creative! You may discover new tastes and recipes you and your family enjoy.

\section{Summary}

Our bodies need sodium to work properly. However, eating too much sodium can lead to serious health problems. To lower your risk for these problems, talk to your healthcare provider and follow the MyPlate recommendation to reduce your sodium intake. Following the simple suggestions provided in this publication will help you reduce your sodium intake. 


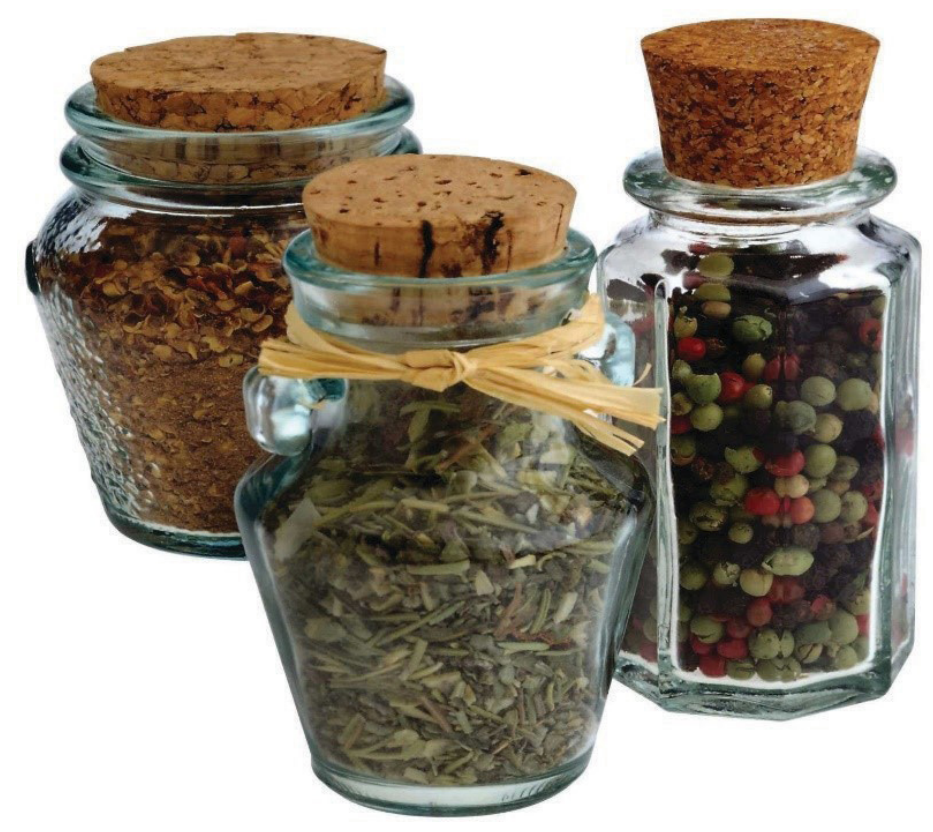

Figure 4. Instead of salt, use different spices such as pepper, basil, cilantro, or oregano to give flavor to your dishes. To lower your sodium intake, avoid using spices with salt in the name or on the ingredients list.

Credits: Brand X Pictures

\section{Recommended Resources}

To learn more about reducing your sodium intake, contact the UF/IFAS Extension Family and Consumer Sciences (FCS) educator in your county. Contact information can be found in the blue pages of your telephone book or online at https://sfyl.ifas.ufl.edu/find-your-local-office/.

USDA’s MyPlate: https://www.myplate.gov/

This site contains information regarding USDA's MyPlate and information about all of the food groups.

USDA Dietary Guidelines for Americans, 2020: https:// www.dietaryguidelines.gov/sites/default/files/2021-03/ Dietary_Guidelines_for_Americans-2020-2025.pdf

This publication contains evidence-based information and nutrition recommendations.

\section{U.S. Food and Drug Administration: So-}

dium in Your Diet: https://www.fda.gov/food/

nutrition-education-resources-materials/sodium-your-diet

This article provides information about reading the food label, nutrient claims on food packaging, and tips for reducing sodium intake.

\section{Nutrition for Health and Fitness: Sodium in Your Diet:} https://edis.ifas.ufl.edu/publication/HE696
Published by UF/IFAS Extension, this article contains evidence-based information related to sodium in our diets. It also includes additional tips for cooking with less sodium.

\section{References}

American Heart Association. (2021, November 1). How much sodium should I eat per day? Retrieved from https:// www.heart.org/en/healthy-living/healthy-eating/eat-smart/ sodium/how-much-sodium-should-i-eat-per-day.

American Heart Association. (2016, October 31). Shaking the Salt Habit to Lower High Blood Pressure.Retrieved from https://www.heart.org/ en/health-topics/high-blood-pressure/changesyou-can-make-to-manage-high-blood-pressure/ shaking-the-salt-habit-to-lower-high-blood-pressure.

American Heart Association. (2018, May 23). Sodium Sources: Where does all that sodium come from? Retrieved from https://www.heart.org/en/healthy-living/ healthy-eating/eat-smart/sodium/sodium-sources.

American Heart Association. (2019). Hypertension Guideline Toolkit. Retrieved from http:// aha-clinical-review.ascendeventmedia.com/books/ aha-high-blood-pressure-toolkit/.

American Heart Association. (2018, May 23). How to Reduce Sodium. Retrieved from https://www.heart.org/ en/healthy-living/healthy-eating/eat-smart/sodium/ how-to-reduce-sodium.

Foods High In.net. (2021). Nuts, Seeds, and Spices High in Sodium. Retrieved from http://foods-high-in.net/ foodshigh-in-sodium/nuts-seeds-and-spices, $8 . h t m l$.

Mayo Clinic. (2021, February 24). 10 Ways to Control High Blood Pressure without Medication. Retrieved from https://www.mayoclinic.org/diseases-conditions/ high-blood-pressure/in-depth/high-blood-pressure/ art-20046974.

Mayo Clinic. (2020, October 19). High Blood Pressure (Hypertension). Retrieved from https://www. mayoclinic.org/diseases-conditions/high-blood-pressure/ symptoms-causes/syc-20373410.

Mayo Foundation for Medical Education and Research. (2019, June 29). Sodium: How to Tame Your Salt Habit. Retrieved from https://www.mayoclinic.org/healthylifestyle/nutrition-and-healthy-eating/in-depth/sodium/ art-20045479. 
MedlinePlus. (2021, July 29). How to Prevent High Blood Pressure. Retrieved from https://medlineplus.gov/howtopreventhighbloodpressure.html.

U.S. Department of Agriculture. (2020, December). Key Recommendations. In Dietary Guidelines for Americans: 2020-2025. Retrieved from https://dietaryguidelines.gov/ sites/default/files/2021-03/Dietary_Guidelines_for_Americans_2020-2025.pdf.

U.S. Food and Drug Administration. (2021, June 8). Sodium in Your Diet. Retrieved from https://www.fda.gov/food/ nutrition-education-resources-materials/sodium-your-diet. 